zones for gravitational reasons; the resulting inhomogeneity in blood flow and blood volume would reduce the measured $K C O$. All published data on changes with age are derived from cross-sectional studies. The only cohort study of $>8 \mathrm{yrs}$ of $T$ L,CO and KCO is that of WATSON et al. [20] who followed up, among others, 29 male never-smokers (mean age $37 \mathrm{yrs}$ at start) over a $22-y r$ period. They found no change in the KCO.

We understand that a joint working party of the American Thoracic Society and the European Respiratory Society is currently reviewing reference values for spirometry, lung volumes and the transfer factor. We hope the carbon monoxide transfer coefficient will not be neglected, since the current recommendations are unsatisfactory. Ideally, values for total lung capacity should be obtained from the same individuals used to obtain reference values for the single breath transfer factor of the lung for carbon monoxide and the carbon monoxide transfer coefficient, so that the effects of poor inflation and/or true differences in total lung capacity at a given height and age can be allowed for [17].

\section{J.M.B. Hughes, N.B. Pride}

Respiratory Medicine, National Heart and Lung Institute, Imperial College, Hammersmith Hospital, London, UK.

\section{References}

1. Hughes JMB, Pride NB. In defence of the carbon monoxide transfer coefficient KCO (TL/VA). Eur Respir J 2001; 17: 168174.

2. Krogh M. The diffusion of gases through the lungs of man. J Physiol 1915; 49: 271-296.

3. Cotes JE, Chinn DJ, Quanjer PH, Roca J, Yernault J-C. Standardization of the measurement of transfer factor (diffusing capacity). Eur Respir J 1993; 6: Suppl. 16, 41-52.

4. American Thoracic Society. Single breath carbon monoxide diffusing capacity (transfer factor), recommendation for a standard technique - 1995 update. Am J Respir Crit Care Med 1995; 152: 2185-2198.

5. Love RG, Seaton A, Quanjer PH. About the ECCS summary equations (letters). Eur Respir J 1990; 9: 489-490.

6. Quanjer PH. Standardised lung function testing. Report of a Working Party of the European Community for Coal and Steel. Bull Eur Physiopathol Respir 1983; 19: Suppl. 5, 45-51.

7. British Thoracic Society and Association of Respiratory Technicians and Physiologists. Guidelines for the measurement of respiratory function. Respir Med 1994; 88: 165-194.
8. van Ganse WF, Ferris BG, Cotes JE. Cigarette smoking and pulmonary diffusing capacity (transfer factor). Am Rev Respir Dis 1972; 105: 30-40.

9. Salorinne Y. Single breath pulmonary diffusing capacity: reference values and application in connective tissue diseases and in various lung diseases. Scand J Respir Dis Suppl 1976; 96: $1-86$.

10. Crapo RO, Gardner RM. Single breath carbon monoxide diffusing capacity (transfer factor), recommendations for a standard technique. Am Rev Respir Dis 1987; 136: 2991307.

11. Miller A, Thornton JC, Warshaw R, Anderson A, Teirstein AS, Selikoff IJ. Single breath diffusing capacity in a representative sample of the population of Michigan, a large industrial state. Am Rev Respir Dis 1983; 127: 270-277.

12. Paoletti P, Viegi G, Pistelli G, et al. Reference equations for the single-breath diffusing capacity: A cross-sectional analysis and effect of body size and age. Am Rev Respir Dis 1985; 132: 806-813.

13. Knudson RJ, Kaltenborn WT, Knudson DE, Burrows B. The single breath carbon monoxide diffusing capacity: Reference equations derived from a healthy non-smoking population and effects of hematocrit. Am Rev Respir Dis 1987; 135: 805-811.

14. Roca J, Rodriguez-Roisin R, Cobo E, Burgos F, Perez J, Clausen JL. Single breath carbon monoxide diffusing capacity prediction equations from a Mediterranean population. Am Rev Respir Dis 1990; 141: 1026-1032.

15. Roberts CM, MacRae KD, Winning AJ, Adams L, Seed WA. Reference values and prediction equations for normal lung function in a non-smoking white urban population. Thorax 1991; 46: 643-650.

16. Gulsvik A, Bakke P, Humerfelt S, et al. Single breath transfer factor for carbon monoxide in an asymptomatic population of never smokers. Thorax 1992; 47: 167-173.

17. Chinn DY, Cotes JE, Flowers R, Marks A-M, Read JW. Transfer factor (diffusing capacity) standardized for alveolar volume: validation, reference values and application of a new linear model to replace KCO (TL/VA). Eur Respir J 1996; 9: 1269-1277.

18. Ogilvie CM, Forster RE, Blakemore WS, Morton JW. A standardized breath holding technique for the clinical measurement of the diffusing capacity of the lung for carbon monoxide. J Clin Invest 1957; 36: 1-17.

19. American Thoracic Society. Lung function testing: selection of reference values and interpretative strategies. Am Rev Respir Dis 1991; 144: 1202-1218.

20. Watson A, Joyce H, Pride NB. Changes in carbon monoxide transfer over 22 years in middle-aged men. Respir Med 2000; 94: 1103-1108.

\title{
Exhaled breath condensate contains more than only volatiles
}

\section{To the Editors:}

I read with interest the review of Woop et al. [1] on biomarkers of lipid peroxidation. I would like to congratulate the authors on this well-detailed overview of the topic. At the same time I would also like to point out that their statement saying "breath condensate samples...rely on the volatility of the substances being measured" is false. If, by this, the authors mean that only volatile substances can be captured in condensate samples they are misunderstanding this sampling method. The authors may not be familiar with this technique, which may be why they make this comment and also mention that exhaled ethane and penthane are materials being measured in condensate several times in their review. The latter two are present in the gas phase of exhaled breath and are measured directly in the breath and not in the cooled (condensed) sample [2].

The principle of exhaled breath condensate (EBC) collection is cooling the exhaled breath, resulting in a fluid sample that contains evaporated and condensed particles (water, ammonia, etc.) plus some droplets from the airway lining fluid. These droplets are released by turbulent airflow, and possibly by other currently not completely understood mechanisms, and can be added to the water vapour from anywhere 
between the alveoli and the mouth. Therefore, in EBC samples, not only volatiles, but also several other mediators with no volatile characteristics can be found and have been reported, including adenosine, different interleukins $(-4,-5$, -8), interferon- $\gamma$, etc. [3-5]. Regarding markers of lipid peroxidation, EBC contains isoprostanes and thiobarbituric acid-reactive substances [2].

The authors are right in saying that there are methodological limitations to this type of sampling. However, this is mainly due to the limited understanding of solute formation and dilution of samples, and the accuracy of some of the currently available methods for measuring mediators in EBC. I agree that ambient air may influence the levels of exhaled biomarkers in EBC and this is shown for hydrogen peroxide [6]. Volatility may be a problem when measuring mediators from $\mathrm{EBC}$, not because the sampling relies on this characteristic, but because if a molecule is volatile it is very hard to figure out the result of its equilibration between the gas and the fluid phase while breath condensation is ongoing. A good example is the ammonia measurement $[7,8]$.

Despite the misinterpretation of exhaled breath condensate, I believe that this review is a valuable source of knowledge and references on lipid peroxidation, with detailed information on the limitations and advantages of the current measuring methods.

\section{Horváth}

Dept of Pathophysiology, National Koranyi Institute for Pulmonology, Budapest, Hungary.

\section{References}

1. Wood LG, Gibson PG, Garg ML. Biomarkers of lipid peroxidation, airway inflammation and asthma. Eur Respir $J$ 2003; 21: 177-186.

2. Paredi P, Kharitonov SA, Barnes PJ. Analysis of expired air for oxidation products. Am J Respir Crit Care Med 2002; 166: S31-S37.

3. Huszar É, Vass G, Vizi É, et al. Adenosine in exhaled breath condensate in healthy volunteers and in patients with asthma. Eur Respir J 2002; 20: 1393-1398.

4. Shahid SK, Kharitonov SA, Wilson NM, Bush A, Barnes PJ. Increased interleukin- 4 and decreased interferon- $\gamma$ in exhaled breath condensate of children with asthma. Am J Respir Crit Care Med 2002; 165: 1290-1293.

5. Scheideler L, Manke HG, Schwulera U, Inacker O, Hammerle H. Detection of nonvolatile macromolecules in breath. A possible diagnostic tool? Am Rev Respir Dis 1993; 148: 778-784.

6. Latzin P, Griese M. Exhaled hydrogen peroxide, nitrite and nitric oxide in healthy children: decrease of hydrogen peroxide by atmospheric nitric oxide. Eur J Med Res 2002; 7: 353-358.

7. Effros RM, Hoaglang KW, Bosbous M, et al. Dilution of respiratory solutes in exhaled condensates. Am J Respir Crit Care Med 2002; 165: 663-669.

8. Vass G, Huszár É, Barát E, et al. Comparison of nasal and oral inhalation during exhaled breath condensate collection. Am J Respir Crit Care Med 2003; 167: 850-855.

From the authors:

We thank I. Horváth for his kind comments on our review "Biomarkers of lipid peroxidation, airway inflammation and asthma" [1], and agree that we have been imprecise with the use of the term "breath condensate". The paper would be improved by replacing this term with "exhaled breath" in relation to ethane, pentane and nitric oxide measurements.

While there is an intuitive explanation for the presence of volatile substances in exhaled breath, the mechanisms by which nonvolatile substances enter expired breath are poorly understood and need to be further investigated. 8-iso-prostaglandin $\mathrm{F}_{2 \alpha}$ and malondialdehyde have been measured in breath condensate as markers of lipid peroxidation [2]; however, it is, as yet, unknown whether this medium can be used for reliable measurement of antioxidant defences. Analysis of total and oxidised glutathione concentrations in induced sputum indicates that sputum supernatant is suitable for this purpose [3]. Hence, we stand by our conclusions in this area.

At the moment both sputum induction and breath condensate collection are promising techniques. The most useful sampling technique remains to be determined and this is an important area of future research. Comparison of both sampling methods in a head-to-head study is needed to resolve this issue.

\section{Wood*, P.G. Gibson*, M. Garg ${ }^{\#}$}

*Dept of Respiratory and Sleep Medicine, Hunter Medical Research Institute, John Hunter Hospital and \#Nutrition and Dietetics, University of Newcastle, New South Wales, Australia.

\section{References}

1. Wood LG, Gibson PG, Garg ML. Biomarkers of lipid peroxidation, airway inflammation and asthma. Eur Respir $J$ 2003; 21: 177-186.

2. Paredi P, Kharitonov SA, Barnes PJ. Analysis of expired air for oxidation products. Am J Respir Crit Care Med 2002; 166: S31-S37.

3. Dauletbaev N, Rickmann J, Viel K, Buhl R, Wagner TO, Bargon J. Glutathione in induced sputum of healthy individuals and patients with asthma. Thorax 2001; 56: 1318.

\section{Noneosinophilic asthma}

\section{To the Editors:}

We read with interest the article by BUIST [1] on similarities and differences between asthma and chronic obstructive pulmonary disease. We would like to make some comments on the nature of inflammation in asthma, which the author has mentioned to be predominantly eosinophilic. Patients have been noted to have severe asthma or suffer an exacerbation without an increase in the eosinophil population in the airways [2]. Based on several studies from 1995 onwards with data on eosinophil levels (cut-off values 2-4\%) on bronchial biopsy specimens, bronchoalveolar lavage fluid and sputum of asthmatic 